\title{
Editorial
}

\section{Changes in the Editorial Board}

Thanking Co-Editors. We would like to thank the following retiring Co-Editors for their outstanding efforts in ensuring the quality of the Journal of Theoretical and Applied Electronic Commerce Research publications: Joan Cooper (University of New South Wales), Paula Swatman (University of South Australia). Joan and Paula have completed a two year term and due to new academic commitments they have vacated their positions as co-editors, but they will continue as valued members of the editorial board. Joan has taken a new position as Pro-Vice Chancellor (Students) \& Registrar at the University of New South Wales. Australia. Paula has vacated her co-editor role to devote more time to other commitments in her current appointment. We thank Joan and Paula because they were initial editorial board members of JTAER and their previous work in collaborative electronic commerce technology and research inspired the creation of our journal.

Welcome New Co-Editors. We welcome Professor Claudia Linnhoff-Popien and Professor Eduard Babulak as new Co-Editors of JTAER. Claudia is currently appointed at the University of Munich, Germany, and Eduard has an appointment at the Fairleigh Dickinson University in Vancouver, Canada.

Claudia Linnhoff-Popien is a full professor of Mobile and Distributed Systems at the Ludwig-Maximilians-University Munich, Germany. She received her Ph.D. degree from the Aachen University of Technology. In addition to her research activities she gave lectures at the University GH Essen, and was a research visitor at the Department of Computer Science, Washington University of St. Louis, Missouri, USA. Her research interests include ubiquitous computing, mobility and mobile commerce, service discovery and context awareness. Her research is supported by Siemens, BMW and several public research funding organizations.

Professor Babulak has published and presented numerous International Journal and Conference papers, Invited Keynotes, Plenary, Panel, Conference, and Colloquial Talks worldwide. He has worked in academia in areas such as Mathematics, Electrical, Computer Engineering and Computing Science in USA, Canada, UK, Spain, Germany, Austria, Cyprus, Turkey, Czech Republic and Slovakia. His academic and engineering work was recognized internationally by the Canadian Association of Professional Engineers, Engineering Council in UK and European Federation of Engineers. His research interests are in E-Commerce, MIS, IT, Ubiquitous Computing, Educational Technologies, E-Manufacturing, Quality of Service provision, Computer Networks, Telematics and Telecommunications Communications Infrastructures, Electronic Health Record and Automation.

Editorial Board Members. The Journal of Theoretical and Applied Electronic Commerce Research has benefited considerably from the services of three editorial board members who are leaving the editorial board: Arne Krokan (Norwegian University of Science and Technology, Norway), Huang Lihua (Fudan University, China), and Petra Schubert (University of Applied Sciences Basel, Switzerland). Dr. Krokan and Dr. Lihua have completed their serving period as members of the EB. We wish them all the best in their current activities. Petra is resigning in order to devote more time to her new appointment at the University of Koblenz-Landau. We wish her the best as she assumes her new responsibilities.

And finally, we would like to welcome the following researchers who have accepted our invitation to serve as new editorial board members for the period 2008-2010:

- Norman Archer (McMaster University, Canada)

- Harry Bouwman (Delft University of Technology, The Netherlands)

- Jerry Gao (San Jose State University, USA)

- $\quad$ Axel Kupper (University of Munich, Germany)

- $\quad$ Yinsheng Li (Fudan University, China)

- $\quad$ Euripidis N. Loukis (University of the Aegean, Greece)

- Joaquim Arnaldo Martins (University of Aveiro, Portugal)

- Carolyn McGregor (University of Ontario Institute of Technology, Canada)

- Paraskevi Mentzelou (Technological Educational Institute of Thessaloniki, Greece) 
- Peter Reichl (Telecommunications Research Center Viena (ftw.), Austria)

- Marcos Sepúlveda (Pontificia Universidad Católica de Chile, Chile)

- $\quad$ Steven Walczak (University of Colorado - Denver, USA)

\section{Narciso Cerpa}

\section{Editor-in-Chief}

Journal of Theoretical and Applied Electronic Commerce Research

www.jtaer.com

April 2008 